\title{
Study of the biodynamic response of the foot to vibration exposure
}

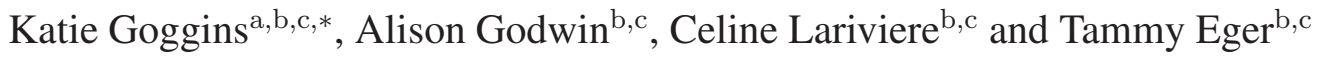 \\ ${ }^{a}$ Bharti School of Engineering, Laurentian University, Sudbury, ON, Canada \\ ${ }^{\mathrm{b}}$ School of Human Kinetics, Laurentian University, Sudbury, ON, Canada \\ ${ }^{\mathrm{C}}$ Centre for Research in Occupational Safety and Health, Laurentian University, Sudbury, ON, Canadas
}

\begin{abstract}
.
BACKGROUND: Exposure to foot-transmitted vibration (FTV) has been linked to injury; however, the biodynamic response of the foot to FTV has not been quantified.

OBJECTIVE: The objective was to measure vibration transmissibility from the floor-to-ankle, and the floor-to-metatarsal, during exposure to FTV while standing, and to determine if FTV exposure frequency, or participant mass or arch index (AI) influence the transmission of FTV through the foot.

METHODS: Participants' AI was measured. Four ADXL326, tri-axial accelerometers were utilized to measure vibration on the platform medial to distal head of first metatarsal, on the distal head of first metatarsal, on the platform paralleling the medial malleolus, and on the lateral malleolus. Participants were randomly exposed to FTV at $25 \mathrm{~Hz}, 30 \mathrm{~Hz}, 35 \mathrm{~Hz}, 40 \mathrm{~Hz}, 45 \mathrm{~Hz}$, and $50 \mathrm{~Hz}$ for 45 seconds.

RESULTS: Neither the three-way interaction of location*frequency*AI $[\lambda=0.816, \mathrm{~F}(5,24)=1.080, p=0.396]$ or location*frequency*mass $[\lambda=0.959, \mathrm{~F}(5,24)=0.203, p=0.958]$ were significant $(p<0.05)$. The location*frequency interaction was significant $[\lambda=0.246, \mathrm{~F}(5,25)=15.365, p=0.0001]$. Differences in mean transmissibility between the ankle and metatarsal were significant at $40 \mathrm{~Hz}, 45 \mathrm{~Hz}$, and $50 \mathrm{~Hz}(p<0.001)$.

CONCLUSIONS: The greatest transmissibility magnitude measured at the metatarsal and ankle occurred at $50 \mathrm{~Hz}$ and $25-$ $30 \mathrm{~Hz}$ respectively, suggesting the formation of a local resonance at each location.
\end{abstract}

Keywords: Foot-transmitted vibration, standing vibration, biodynamic response, vibration-induced white-feet

\section{Introduction}

Exposure to foot-transmitted vibration (FTV) occurs when vibration enters the body at the feet and is transmitted through the feet and legs from vibrating tools, vibrating machinery, or standing on vibrating platforms or surfaces [1-3]. FTV exposure has been reported in mining, farming, forestry and construction [2,4-6]. Miners can be exposed to FTV when operating locomotives, bolters, jumbo drills, or drills attached to platforms workers stand on [2] and several researchers have published reports indicating miners have reported pain, discomfort, and blanching in the toes more often than co-workers not exposed to vibration via the feet $[2,3,7]$.

Researchers studying the effects of hand-arm-vibration syndrome (HAVS) have found a correlation between the neurological and vascular symptoms observed in the upper extremities and symptoms observed in the feet of workers affected by HAVS. Raynaud's phenomenon of the feet has been examined

\footnotetext{
${ }^{*}$ Corresponding author: Katie Goggins, Centre for Research in Occupational Safety and Health, 935 Ramsey Lake Road, Sudbury, ON, Canada. Tel.: +1 705919 5359; E-mail: kx_goggins@laurentian.ca.
}

1359-9364/16/\$35.00 (C) 2016 - IOS Press and the authors. All rights reserved This article is published online with Open Access and distributed under the terms of the Creative Commons Attribution NonCommercial License. 
mostly in conjunction with HAVS [7-13]. Given the similarities between the anatomy of the hands and feet it is not unreasonable to speculate that their resonant frequencies would be in the same range. The literature suggests the finger-hand-arm system is most susceptible to vibration at higher frequencies (40-100 Hz for the hand-arm system, $>100 \mathrm{~Hz}$ for the fingers [14]). Furthermore, the prevalence of vascular-induced disorders associated with hand-transmitted vibration (HTV) tends to be greater in workers using tools that have dominant frequencies greater than $63 \mathrm{~Hz}$ [15]. Determining potential health risks associated with FTV are problematic as the current standard for evaluating exposure to vibration when standing, ISO 2631-1 [16] might not be appropriate for FTV exposures observed in mining [3]; however, the standard for evaluating segmental exposure to vibration, ISO 5349-1 [17] does not consider FTV. In order to determine the most appropriate standard for assessing health risks associated with FTV further information regarding the biodynamic response and resonant frequency of the foot is required.

Biodynamic response is the relationship between human physiology and environmental stimuli. A number of intrinsic and extrinsic factors influence human response to vibration. Intrinsic variables can include population type (age, sex, size, and health), experience, body posture, and types of activities [16]. Conversely extrinsic variables can include vibration magnitude, vibration frequency, vibration axis, vibration input position, vibration duration, and other influences such as noise, heat, acceleration, and light $[16,18,19]$. When evaluating the biodynamic response of the human body to vibration, an understanding of the resonant frequency and transmissibility is required. Resonant frequency is the point at which maximum displacement between organs and skeletal structures occurs, thereby placing strain on the body tissue involved [20], causing vibration exposure at resonance to be directly linked with increased injury risk. Maximal transmissibility occurs at a structure's resonant frequency. Transmissibility is a measure of the ability of the body to either amplify or suppress input vibration. A variety of biodynamic responses, particularly those between the point at which vibration enters the body and the point at which it is measured are reflected in the transmissibility of the human body [21]. Transmissibility is defined as the ratio of the vibration measured between two points [22], where amplification is represented by a transmissibility value higher than 1.0 , and attenuation is considered to occur with a transmissibility value lower than 1.0.

Due to differences in structure, each region of the body has a different resonant frequency. The frequency at which the hand-arm system is believed to be at greatest risk of injury is in the 20-40 Hz range, while the fingers are at greater risk above $100 \mathrm{~Hz}[14,19]$, because exposure at these frequencies leads to vibration amplification. In a study examining the absolute threshold of the feet, for a seated person exposed to FTV, Forta et al. [23] found the absolute threshold to occur between 8-25 Hz and all participants indicated they felt vibration most at the sole of the feet when exposed to FTV at $125 \mathrm{~Hz}$. Although this study offered some evidence of the biodynamic response, of the foot to FTV, it did not evaluate absolute threshold when a person was standing nor did it measure transmissibility or report resonance values for the feet. Singh [24] examined vibration transmissibility via the feet in standing individuals and reported the z-axis vibration was lower at the ankle in all but one male participant, suggesting that anatomical structures such as the heel fat pad may play a role in attenuating FTV from the floor to the ankle. Harazin and Grzesik [25] examined the transmission of vertical WBV in ten standing subjects for ten postures at six body segments and found the magnitude of vibration being transmitted by the foot to be amplified in the frequency range of $31.5-125 \mathrm{~Hz}$ at the metatarsus and at $25-63 \mathrm{~Hz}$ at the ankle (malleolus medialis), implying the formation of a local resonance within the foot. However, the Harazin and Grzesik study [25] was limited to ten subjects and did not take into account any anthropometric measurements of the foot. 
A number of variables can potentially affect the biodynamic response of the body to FTV, including participant mass and arch type. The surface area of the foot in contact with the floor surface can vary depending on arch type; individuals with a higher arch will have less area in direct contact with a vibrating surface than those with a low arch. Absolute threshold is the lowest intensity at which vibration stimuli can be detected 50\% of the time [26]. Morioka and Griffin [26] examined mean vibration perception thresholds as a function of frequency at three locations on the hand; distal finger, distal palm, and proximal palm. Findings indicated that thresholds reduced systematically as the contact area increased from the fingertip to the whole hand. The palm had a larger surface area for vibration to be transmitted through resulting in lower vibration sensitivity. The same mechanoreceptive afferent nerve fibres are present in the feet as well as the hands; therefore, the reported differences between transmission at the fingers and the palm of the hand [26] suggests vibration might transmit through the foot differently at the toes and the heel.

Therefore, the primary purpose of this study was to measure the transmission of vibration from the floor-to-ankle (FTA), and the floor-to-metatarsal (FTM), during exposure to FTV while standing. The influence of FTV exposure frequency, participant mass and participant arch index on FTA and FTM transmissibility was also examined. It was hypothesized that FTM transmissibility will be greater than FTA transmissibility because there is more mass distributed through the ankle than the metatarsals and the toes can move more freely when standing. FTM transmissibility was also hypothesized to be greater than FTA transmissibility at higher frequencies $(45$ and $50 \mathrm{~Hz})$ compared to lower frequencies $(25$ and $30 \mathrm{~Hz}$ ) based on the response of the fingers and palm to similar exposure frequencies [14]. Furthermore, it was hypothesized that participants with higher arches (lower foot surface area in contact with the vibrating surface) would have lower FTA transmissibility than participants with lower arches.

\section{Methods}

Laurentian University's Research Ethics Board approved the procedures in this study and all participants gave informed consent prior to study participation.

\subsection{Participants}

Thirty male participants with an average age of $28( \pm 9.5)$ years, height of $180.6( \pm 8.7) \mathrm{cm}$, and mass of $85.65( \pm 12.4) \mathrm{kg}$ were recruited from a sample of convenience (Table 1). Participants had no history of musculoskeletal injury, vasculopathy, neuropathy, motion sickness, diabetes, or head injury in the 6-months prior to testing. Participants with a previous head injury were excluded because the FTV exposures evaluated in this study can travel through the body and be amplified at the head, which could increase discomfort in individuals recovering from a head injury.

\subsection{Arch type assessment}

Prior to the vibration exposure protocol, each participant's foot arch type was classified using the foot imprint technique developed by Cavanagh and Rogers [27]. Arch index (AI) is defined as the ratio of the area of the middle third of the toeless footprint (truncated foot) to the total footprint area [27]. An AI of less than 0.21 indicates a high arch while an AI of greater than 0.26 indicates a low arch (Table 1). To calculate the AI participants were required to immerse the bottom portion of their right foot into a box containing edible colorant and then step onto graph paper consisting of $0.36 \mathrm{~cm}^{2}$ grids with their full 
Table 1

Summary of participant demographic information

\begin{tabular}{ccccc}
\hline Participant \# & Age (years) & Height $(\mathrm{cm})$ & Mass $(\mathrm{kg})$ & Arch index \\
\hline 1 & 20 & 178 & 81.4 & 0.22 \\
2 & 21 & 186 & 90.7 & 0.26 \\
3 & 22 & 189 & 90.7 & 0.26 \\
4 & 33 & 167 & 87.0 & 0.25 \\
5 & 24 & 181 & 88.4 & 0.34 \\
6 & 21 & 193 & 104.3 & 0.28 \\
7 & 38 & 194 & 93.4 & 0.20 \\
8 & 21 & 189 & 97.2 & 0.27 \\
9 & 26 & 188 & 97.0 & 0.22 \\
10 & 56 & 179 & 82.5 & 0.31 \\
11 & 30 & 167 & 85.2 & 0.32 \\
12 & 28 & 185 & 85.2 & 0.25 \\
13 & 22 & 175 & 57.6 & 0.26 \\
14 & 28 & 161 & 83.6 & 0.26 \\
15 & 43 & 200 & 121.5 & 0.30 \\
16 & 19 & 177 & 63.2 & 0.20 \\
17 & 21 & 180 & 77.1 & 0.26 \\
18 & 20 & 180 & 75.2 & 0.26 \\
19 & 46 & 184 & 85.2 & 0.18 \\
20 & 28 & 173 & 93.4 & 0.30 \\
21 & 34 & 178 & 90.7 & 0.26 \\
22 & 21 & 174 & 74.8 & 0.20 \\
23 & 32 & 181 & 80.7 & 0.12 \\
24 & 23 & 170 & 72.1 & 0.26 \\
25 & 25 & 190 & 90.0 & 0.25 \\
26 & 20 & 181 & 69.4 & 0.27 \\
27 & 45 & 183 & 97.7 & 0.22 \\
28 & 19 & 173 & 89.3 & 0.29 \\
29 & 20 & 185 & 77.5 & 0.22 \\
30 & 23 & 178 & 86.1 & 0.28 \\
Mean & 27.6 & 180.6 & 85.65 & 0.25 \\
SD & 9.5 & 8.7 & 12.37 & 0.05 \\
\hline & & & & \\
\hline
\end{tabular}

body weight, leaving their functional foot impression on the paper. Once the graph paper dried the AI was calculated according to Eq. (1) using the surface area divisions from Fig. 1 [27].

$$
\text { Arch Index }(A I)=\frac{B}{(A+B+C)}
$$

Where $A$ is the surface area of the forefoot, $B$ is the surface area of the midfoot, and $C$ is the surface area of the hind foot [27].

\subsection{Vibration exposure}

An exercise vibration platform (Power Plate North American, Inc., Irvine, CA) was utilized to generate six different frequencies of vibration, including: $25 \mathrm{~Hz}, 30 \mathrm{~Hz}, 35 \mathrm{~Hz}, 40 \mathrm{~Hz}, 45 \mathrm{~Hz}$ and $50 \mathrm{~Hz}$ (Table 2). The vibration platform was calibrated to confirm the corresponding running root-mean-squared (RMS) un-weighted average acceleration values and coherence at each frequency. These particular frequencies were selected to simulate the range of vibration frequencies experienced by miners exposed to FTV when drilling off platforms and raises used in underground mining [3]. Participants were randomly exposed to each vibration frequency for 20 seconds (with one repeat) to become accustomed to the 
Table 2

FTV exposure profile characteristics

\begin{tabular}{cc}
\hline $\begin{array}{c}\text { Dominant z-axis (vertical) FTV } \\
\text { exposure frequency }(\mathrm{Hz})\end{array}$ & $\begin{array}{c}\text { Running RMS un-weighted mean z-axis (vertical) } \\
\text { acceleration }\left(\mathrm{m} / \mathrm{s}^{2}\right)\end{array}$ \\
\hline 25 & 8 \\
30 & 10 \\
35 & 12 \\
40 & 13 \\
45 & 14 \\
50 & 14 \\
\hline
\end{tabular}

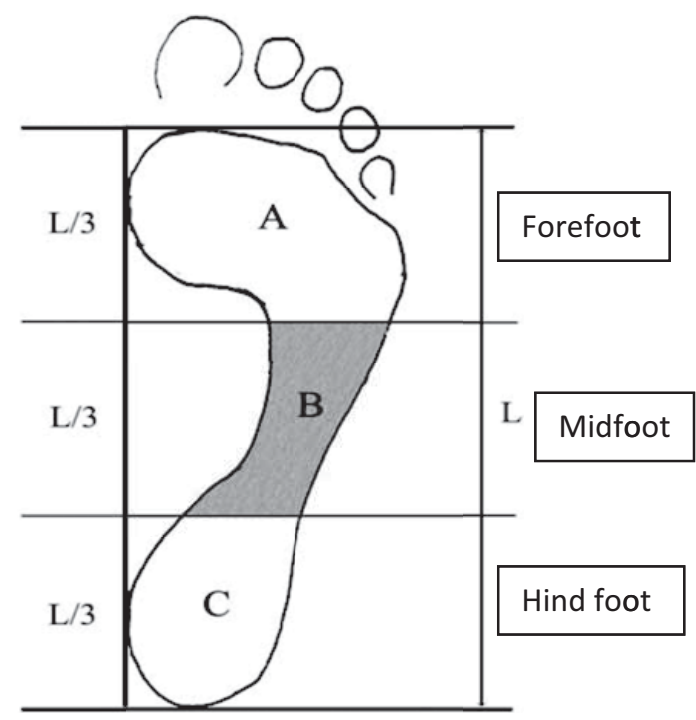

Fig. 1. Footprint divisions used for the arch index measurement [29].

exposure. Participants were then randomly exposed to each of the six frequencies of vibration for 45 seconds. During the 45 second exposure period FTM and FTA vibration transmissibility was measured. Participants rested for 10-seconds after each 45 second vibration exposure [4].

\subsection{Vibration measurement equipment and data collection}

Four ADXL326, $19 \mathrm{~g}$ tri-axial accelerometers (custom design University of Windsor, ON) were utilized to measure vibration, at the following locations:

(1) Directly on the vibration platform medial to the distal head of the first metatarsal;

(2) Directly on the skin at the distal head of the first metatarsal;

(3) Directly on the vibration platform paralleling the medial malleolous; and

(4) Directly on the skin at the lateral malleolus (Fig. 2).

Data were collected at a sampling frequency of $1000 \mathrm{~Hz}$ and stored on two portable dataloggers, DataLOG II P3X8 (Biometrics, Gwent, UK). Participants were instructed to stand on the vibration platform in a comfortable neutral posture and align their heels over two marked positions. Participants were then instructed to stand with a slight bend in their knees and to relax their shoulders and place their hands comfortably to their sides. Finally, participants were reminded not to hold onto the handles above the 

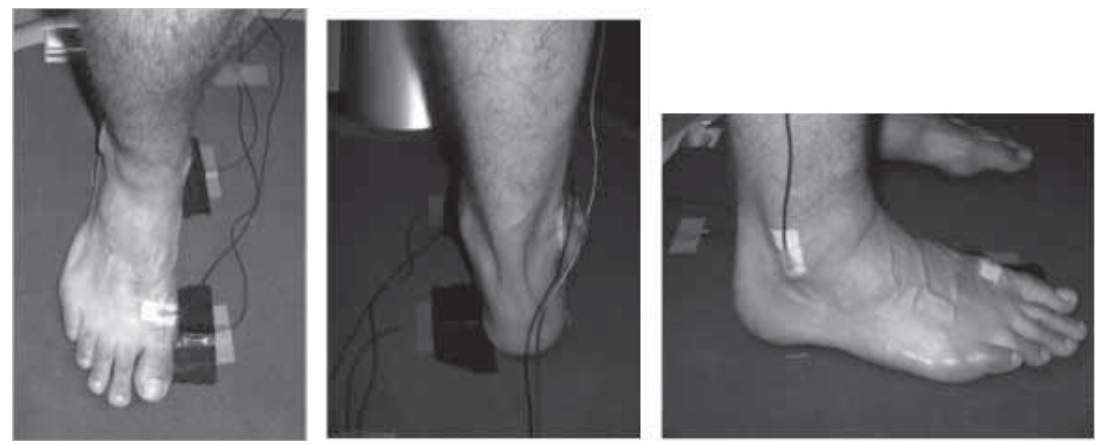

Fig. 2. Anterior (left), posterior (middle), and lateral (right) views of ADXL326 accelerometer attachments.

platform unless they needed to regain their balance. This was done to ensure vibration entering the body was only through the feet and not the hands and feet.

\subsection{Data analysis}

All vibration data were processed using the Vibratools custom MATlab program (The Mathworks Inc., MA, USA v 7.1.). All data remained un-weighted throughout the data analysis. A multiple resolution cross-correlation (MRXcorr) procedure was used to align both 6-signal data time histories, a process previously validated by Jack et al. [28]. The time histories were then band-pass filtered with the high-pass and low-pass cutoff frequencies set to $0.5 \mathrm{~Hz}$ and $100 \mathrm{~Hz}$ respectively in accordance with ISO 26311 [17]. For each vibration exposure the un-weighted peak accelerations, RMS average accelerations, running RMS accelerations, the dominant 1/3-octave band exposure frequencies, the Discrete Fourier Time Series (DFT) power spectra, and the coherence were computed. The un-weighted peak accelerations were determined by full wave, rectifying the data and selecting the largest recorded acceleration value. The RMS average accelerations were determined using Eq. (2) [17].

$$
a=\left[\frac{1}{T} \int_{0}^{T} a^{2}(t) d t\right]^{\frac{1}{2}}
$$

Where $a$ is the un-weighted RMS average acceleration, $a(t)$ is the un-weighted acceleration as a function of time $(t)$ and $T$ is the measurement duration.

The running RMS average accelerations were calculated using 1-second sliding window averaging with a $90 \%$ overlap (Eq. (3)), and determined for all three basicentric translational axis and exposure frequencies [16].

$$
a\left(t_{0}\right)=\left[\frac{1}{\tau} \int_{t_{0}-\tau}^{t_{0}}[(a(t))]^{2} d t\right]^{\frac{1}{2}}
$$

Where $a\left(t_{0}\right)$ is the un-weighted running RMS average acceleration, $a(t)$ is the instantaneous unweighted acceleration as a function of time $(t), \tau$ is the integration time for the running average, and $t_{0}$ is the time of observation.

Transfer functions were calculated using the cross-spectral density (CSD) method (Eq. (4)) [28,29] across the frequency ranges previously mentioned for all accelerometers. From these transfer functions 
the dominant transmission frequency (frequency with the greatest transfer function modulus magnitude) was determined for all three basicentric translational axis at the metatarsal and ankle.

$$
T_{i o}(f)=\frac{C S D_{i o}(f)}{P S D_{i i}(f)}
$$

Where $T_{i o}$ is the complex transfer function between the platform metatarsal or ankle input (ii) accelerations and the metatarsal and ankle output (oo) accelerations at frequency f. $C S D_{i o}$ indicates a crossspectral density function between the platform input accelerations and accelerations for the output of the metatarsal and ankle. $P S D_{i i}$ represents the power-spectral density of the platform input.

Transmissibility was defined as the ratio of the running RMS acceleration output to input. Transmissibility was calculated at the metatarsal (Eq. (5)) and the ankle (Eq. (6)) in the z-axis for comparison.

$$
T_{\text {metatarsal }}=\frac{a_{z}(T D 02)}{a_{z}(T D 01)}
$$

Where $T_{\text {metatarsal }}$ is the transmissibility at the metatarsal, $\mathrm{a}_{z}$ (TD02) is the un-weighted running RMS average acceleration on top of the metatarsal, and $\mathrm{a}_{z}$ (TD01) is the un-weighted running RMS average acceleration on the platform at the metatarsal.

$$
T_{\text {ankle }}=\frac{a_{z}(T D 04)}{a_{z}(T D 03)}
$$

Where $\mathrm{T}_{\text {ankle }}$ is the transmissibility at the ankle, $\mathrm{a}_{z}$ (TD04) is the un-weighted running RMS average acceleration on the lateral ankle, and $\mathrm{a}_{z}$ (TD03) is the un-weighted running RMS average acceleration on the platform at the ankle.

In addition to 1/3-octave bandwidth running RMS average acceleration spectra [16] and Discrete Fourier Time Series (DFT) power spectra were also determined using a 1-second Hanning window with the same $90 \%$ overlap as the $1 / 3$-octave band running RMS average acceleration analysis.

The degree of the correlation between the input and output was expressed in terms of the coherence (Eq. (7)). Coherence being a value between 0 and 1, the greater the coherence the greater the correlation between the two signals being analyzed [30].

$$
\text { coherence }(f)^{2}=\frac{\left|C S D_{\text {input-output }}(f)\right|^{2}}{P S D_{\text {input }}(f) x \operatorname{PSD}_{\text {output }}(f)}
$$

Where CSD is the cross-spectral density and PSD is the power spectral density.

For the purpose of this paper the RMS average accelerations, the dominant 1/3-octave band exposure frequencies, FTA transmissibility, FTM transmissibility, and the coherence were evaluated.

\subsection{Statistical analysis}

For all statistical analyses, the dependent variable was transmissibility, measured as a ratio between the running RMS acceleration input to output. The independent variables were location with two levels (toe; ankle), arch index with two levels (high; low) and frequency with six levels ( $25 \mathrm{~Hz} ; 30 \mathrm{~Hz} ; 35 \mathrm{~Hz}$; $40 \mathrm{~Hz} ; 45 \mathrm{~Hz} ; 50 \mathrm{~Hz}$ ). Prior to any statistical analysis, the data were transformed using a logarithmic transformation (Eq. (8)) [31,32], to ensure the assumption of normality was met.

$$
N E W X=L G 10(X+C)
$$

Where $X$ is the original variable and $C$ is a constant added to each score so that the smallest score is 1 . 


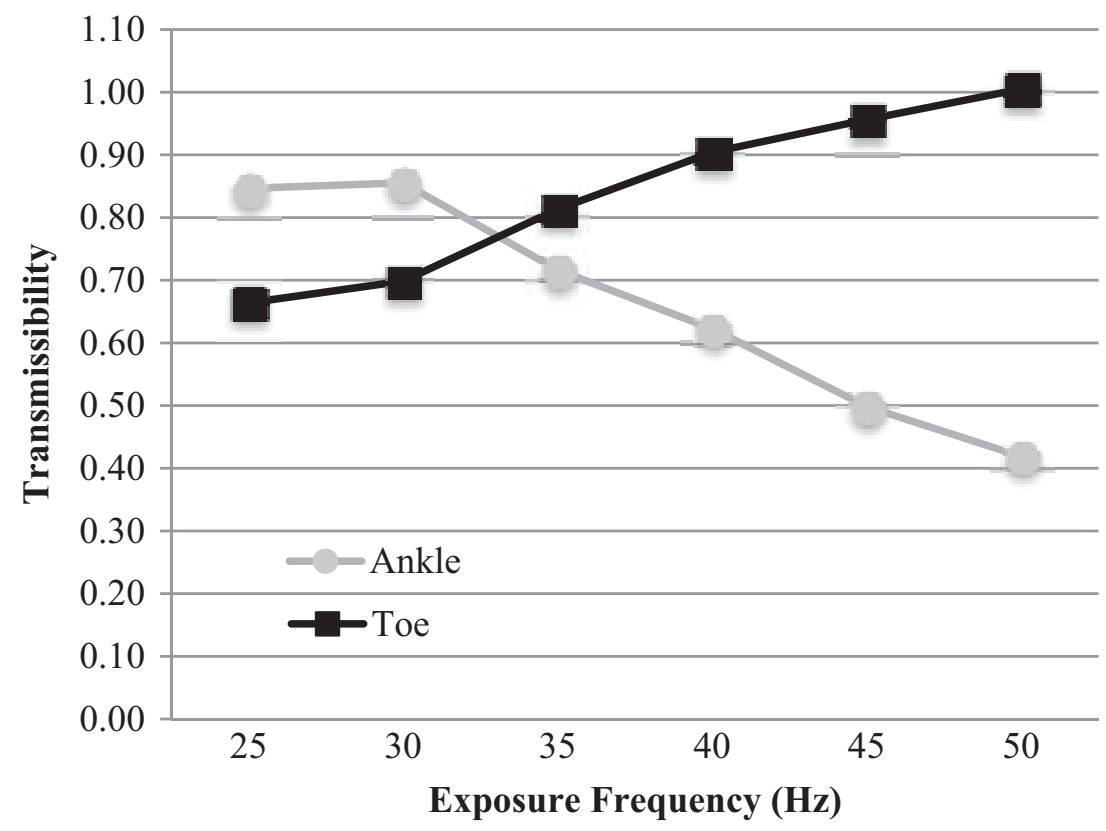

Fig. 3. Average transmissibility of 30 male subjects from floor-to-ankle (grey) and floor-to-metatarsal (black) at six FTV exposure frequencies $(25,30,35,40,45$ and $50 \mathrm{~Hz})$.

\subsubsection{Effects of arch index on transmissibility}

A two-way repeated measures analysis of covariance (RM ANCOVA) was conducted to determine the effect of frequency (independent variable) and location (independent variable) while accounting for the variability due to arch index (covariate) on vibration transmissibility magnitude (dependent variable) at the metatarsal (toe) and ankle. Significance was achieved when $p<0.05$.

\subsubsection{Effects of mass on transmissibility}

A two-way repeated measures analysis of covariance (RM ANCOVA) was conducted to determine the effect of frequency (independent variable) and location (independent variable) while accounting for the variability due to mass (covariate) on vibration transmissibility magnitude (dependent variable) at the metatarsal (toe) and ankle. Significance was achieved when $p<0.05$.

\subsubsection{Effects of location and frequency on transmissibility}

A two-way repeated measures analysis of variance (ANOVA) was conducted to examine the effects of location and frequency (independent variables) on vibration transmissibility magnitude (dependent variable). Significance was achieved when $p<0.05$.

\section{Results}

The mean FTA and FTM transmissibility results for thirty participants are displayed in Fig. 3, and individual transmissibility values are summarized in Table 3 . In general, FTA transmissibility was greater at the lower frequencies and FTM transmissibility was greater at higher frequencies. Mean FTA transmissibility was highest (0.86) at $30 \mathrm{~Hz}$ and mean FTM transmissibility was highest (1.01) at $50 \mathrm{~Hz}$. The 
Table 3

Summary of FTA and FTM transmissibility for each participant at 25, 30, 35, 40, 45 and $50 \mathrm{~Hz}$. Mean transmissibility values greater than 1 are bolded

\begin{tabular}{|c|c|c|c|c|c|c|c|c|c|c|c|c|}
\hline \multirow[t]{3}{*}{ Participant \# } & \multicolumn{6}{|c|}{ FTA transmissibility calculated } & \multicolumn{6}{|c|}{ FTM transmissibility calculated } \\
\hline & \multicolumn{6}{|c|}{ FTV exposure frequency $\mathrm{Hz}$} & \multicolumn{6}{|c|}{ FTV exposure frequency $\mathrm{Hz}$} \\
\hline & 25 & 30 & 35 & 40 & 45 & 50 & 25 & 30 & 35 & 40 & 45 & 50 \\
\hline 1 & 0.96 & 0.74 & 0.74 & 0.75 & 0.61 & 0.63 & 0.77 & 0.66 & 0.84 & 0.84 & 0.98 & 1.02 \\
\hline 2 & 1.35 & 1.72 & 1.20 & 0.77 & 0.58 & 0.30 & 0.33 & 0.69 & 1.05 & 1.08 & 1.12 & 1.16 \\
\hline 3 & 0.59 & 0.83 & 0.96 & 0.72 & 0.47 & 0.51 & 0.85 & 0.91 & 0.88 & 0.95 & 0.98 & 0.98 \\
\hline 4 & 0.92 & 1.11 & 0.89 & 0.39 & 0.27 & 0.12 & 0.88 & 0.97 & 0.96 & 0.76 & 0.75 & 0.77 \\
\hline 5 & 0.24 & 0.98 & 0.48 & 0.30 & 0.23 & 0.17 & 0.61 & 0.52 & 0.73 & 0.77 & 0.92 & 0.90 \\
\hline 6 & 0.89 & 0.70 & 0.58 & 0.53 & 0.43 & 0.34 & 0.47 & 0.68 & 0.89 & 1.03 & 1.02 & 1.05 \\
\hline 7 & 0.84 & 0.90 & 0.78 & 0.75 & 0.60 & 0.53 & 0.65 & 0.66 & 0.89 & 1.00 & 1.05 & 1.07 \\
\hline 8 & 0.36 & 0.58 & 0.45 & 0.22 & 0.15 & 0.14 & 0.81 & 0.76 & 0.95 & 0.99 & 1.06 & 1.10 \\
\hline 9 & 0.83 & 0.58 & 0.87 & 1.11 & 1.24 & 1.15 & 0.52 & 0.39 & 0.42 & 0.66 & 0.88 & 0.98 \\
\hline 10 & 0.89 & 0.48 & 0.39 & 0.27 & 0.24 & 0.13 & 0.57 & 0.68 & 0.79 & 0.94 & 1.04 & 1.04 \\
\hline 11 & 0.88 & 0.77 & 0.89 & 0.71 & 1.30 & 1.39 & 0.82 & 0.82 & 0.81 & 1.19 & 0.82 & 0.64 \\
\hline 12 & 1.00 & 0.90 & 0.84 & 0.50 & 0.32 & 0.21 & 0.38 & 0.43 & 0.55 & 0.85 & 0.92 & 0.98 \\
\hline 13 & 0.62 & 0.96 & 0.61 & 0.64 & 0.45 & 0.59 & 0.73 & 0.82 & 0.95 & 0.91 & 0.91 & 0.78 \\
\hline 14 & 0.61 & 0.70 & 0.59 & 0.52 & 0.41 & 0.22 & 0.67 & 0.62 & 0.77 & 0.85 & 0.95 & 1.04 \\
\hline 15 & 0.30 & 0.27 & 0.26 & 0.13 & 0.14 & 0.15 & 0.64 & 0.73 & 0.81 & 0.92 & 0.94 & 0.98 \\
\hline 16 & 0.72 & 0.76 & 0.71 & 0.40 & 0.23 & 0.19 & 0.52 & 0.79 & 0.90 & 0.92 & 0.93 & 0.95 \\
\hline 17 & 1.50 & 1.72 & 0.65 & 1.04 & 0.32 & 0.22 & 0.84 & 0.85 & 0.92 & 0.77 & 0.89 & 1.00 \\
\hline 18 & 0.39 & 0.48 & 0.73 & 0.54 & 0.41 & 0.36 & 0.77 & 0.84 & 0.98 & 1.01 & 0.96 & 0.98 \\
\hline 19 & 1.00 & 1.04 & 1.13 & 1.09 & 0.78 & 0.65 & 0.71 & 0.64 & 0.56 & 0.62 & 1.11 & 1.33 \\
\hline 20 & 1.05 & 0.69 & 0.71 & 0.51 & 0.34 & 0.27 & 0.56 & 0.63 & 0.69 & 0.86 & 0.99 & 1.08 \\
\hline 21 & 1.15 & 1.12 & 0.92 & 1.01 & 0.86 & 0.30 & 0.76 & 0.69 & 0.60 & 0.73 & 0.66 & 1.01 \\
\hline 22 & 0.95 & 1.02 & 0.83 & 0.77 & 0.61 & 0.39 & 0.55 & 0.54 & 0.73 & 1.04 & 1.03 & 1.09 \\
\hline 23 & 1.00 & 0.76 & 0.52 & 0.59 & 0.48 & 0.43 & 0.66 & 0.68 & 0.80 & 0.96 & 1.02 & 1.01 \\
\hline 24 & 0.60 & 0.64 & 0.63 & 0.59 & 0.51 & 0.49 & 0.45 & 0.69 & 0.84 & 0.91 & 0.94 & 1.00 \\
\hline 25 & 0.89 & 0.78 & 0.65 & 0.51 & 0.32 & 0.32 & 0.82 & 0.92 & 1.29 & 1.30 & 1.35 & 1.42 \\
\hline 26 & 1.52 & 1.46 & 0.71 & 0.44 & 0.19 & 0.13 & 0.41 & 0.69 & 1.00 & 1.11 & 1.08 & 1.01 \\
\hline 27 & 0.63 & 0.37 & 0.19 & 0.12 & 0.06 & 0.09 & 0.74 & 0.80 & 0.88 & 0.94 & 0.98 & 0.99 \\
\hline 28 & 0.93 & 1.23 & 1.01 & 1.12 & 1.04 & 0.80 & 0.71 & 0.68 & 0.64 & 0.66 & 0.69 & 0.81 \\
\hline 29 & 0.67 & 0.57 & 0.73 & 0.64 & 0.50 & 0.42 & 0.66 & 0.65 & 0.70 & 0.83 & 0.93 & 0.98 \\
\hline 30 & 1.16 & 0.80 & 0.84 & 1.02 & 0.85 & 0.93 & 1.03 & 0.54 & 0.56 & 0.73 & 0.81 & 1.02 \\
\hline Mean & 0.85 & 0.86 & 0.72 & 0.62 & 0.50 & 0.42 & 0.66 & 0.70 & 0.81 & 0.90 & 0.96 & 1.01 \\
\hline$S D$ & 0.32 & 0.35 & 0.23 & 0.29 & 0.31 & 0.31 & 0.16 & 0.14 & 0.18 & 0.16 & 0.13 & 0.15 \\
\hline
\end{tabular}

results of a two-way repeated measures ANOVA indicated the location frequency interaction was significant $(\lambda=0.246, \mathrm{~F}(5,25)=15.365, p=0.0001)$. More specifically, differences in mean transmissibility between the ankle and metatarsal were highly significant at $40 \mathrm{~Hz}(p<0.001), 45 \mathrm{~Hz}(p<0.001)$, and $50 \mathrm{~Hz}(p<0.001)$ (Fig. 3).

Peak FTA transmissibility above one, implying amplification, occurred at $25 \mathrm{~Hz}$ for three participants $(20,21,30)$, at $30 \mathrm{~Hz}$ for six participants $(2,4,17,19,22,28)$, at $45 \mathrm{~Hz}$ for one participant (9) and $50 \mathrm{~Hz}$ for one participant (11) (Table 3). Furthermore, peak FTM transmissibility above one occurred at $50 \mathrm{~Hz}$ for thirteen participants, while only one participant (30) had a peak greater than one at 25,30 or $35 \mathrm{~Hz}$ (Table 3). These results are in accordance with the hypothesis that FTM transmissibility would be greater than FTA transmissibility especially at the higher frequencies $(45$, and $50 \mathrm{~Hz})$.

\subsection{Effects of Arch Index (AI) on transmissibility}

The two-way repeated measures ANCOVA revealed that neither the three-way interaction of location*frequency*AI $[\lambda=0.816, \mathrm{~F}(5,24)=1.080, p=0.396]$ or the two-way interaction with location*AI 
$[\lambda=0.989, \mathrm{~F}(1,28)=0.323, p=0.575]$ and frequency*AI $[\lambda=0.932, \mathrm{~F}(5,24)=0.349, p=0.877]$ were significant $(p<0.05)$. This finding does not support our hypothesis that participants with higher arches would have lower FTA transmissibility than participants with lower arches.

\subsection{Effects of mass on transmissibility}

The two-way repeated measures ANCOVA revealed that neither the three-way interaction of location*frequency*mass $[\lambda=0.959, \mathrm{~F}(5,24)=0.203, p=0.958]$ or the two-way interaction with location*mass $[\lambda=0.967, \mathrm{~F}(1,28)=0.959, p=0.336]$ and frequency*mass $[\lambda=0.884, \mathrm{~F}(5,24)=0.627$, $p=0.680]$ were significant $(p<0.05)$.

\subsection{Effects of location and frequency on transmissibility}

A two-way repeated measures ANOVA was conducted to evaluate the effect of location and frequency on vibration transmissibility. The location and frequency main effects and location frequency interaction effect were tested using the multivariate criterion of Wilks' lambda $(\lambda)$. The location frequency interaction was significant $[\lambda=0.246, \mathrm{~F}(5,25)=15.365, p=0.0001]$, the location main effect was significant, $[\lambda=0.644, \mathrm{~F}(1,29)=16.032, p=0.0001]$, and the frequency main effect was significant $[\lambda=0.513$, $\mathrm{F}(5,25)=4.754, p=0.003]$.

Six paired-samples t-tests were conducted to follow up the significant location main effect. Familywise error rate was controlled for across the tests using Holm's sequential Bonferroni approach. Differences in mean transmissibility between the two locations were significant between FTM at $40 \mathrm{~Hz}$ and FTA at $40 \mathrm{~Hz}(\mathrm{t}(29)=4.116, p<0.001)$, between FTM at $45 \mathrm{~Hz}$ and the FTA at $45 \mathrm{~Hz}(\mathrm{t}(29)=6.599$, $p<0.001)$, and between FTM at $50 \mathrm{~Hz}$ and FTA at $50 \mathrm{~Hz}(\mathrm{t}(29)=8.828, p<0.001)$.

Thirty paired-samples t-tests were computed to assess the significant frequency main effect. Differences between the six frequencies were evaluated at both locations separately, controlling for Familywise error rate using Holm's sequential Bonferroni approach. For FTA transmissibility, twelve of the fifteen paired-samples were significant, the three pairs which were not significantly different were those at the lower frequencies FTA at $25 \mathrm{~Hz}-$ FTA at $30 \mathrm{~Hz}(\mathrm{t}(29)=-0.114, p=0.910)$, FTA at $25 \mathrm{~Hz}-$ FTA at $35 \mathrm{~Hz}(\mathrm{t}(29)=2.094, p=0.045)$, and FTA at $30 \mathrm{~Hz}-\mathrm{FTA}$ at $35 \mathrm{~Hz}(\mathrm{t}(29)=2.402, p=0.022)$. Finally, fifteen paired-samples t-tests were completed using tetrad comparisons, involving four means to evaluate whether the mean differences between the two locations are the same between any two frequencies, again controlling for Familywise error rate using Holm's sequential Bonferroni approach. All pairs were significantly different, except for the differences between FTM at $25 \mathrm{~Hz}$ - FTA at $25 \mathrm{~Hz}$ and FTM at $30 \mathrm{~Hz}$ - FTA at $30 \mathrm{~Hz}$.

\section{Discussion}

In order to measure the biodynamic response of the foot to vibration, participants were exposed to FTV at $25 \mathrm{~Hz}, 30 \mathrm{~Hz}, 35 \mathrm{~Hz}, 40 \mathrm{~Hz}, 45 \mathrm{~Hz}$, and $50 \mathrm{~Hz}$. An interaction between FTV exposure frequency and the location of transmissibility measurement (FTM compared with FTA) was found (Fig. 3). The interaction suggests FTM and FTA transmissibility at 25 and $30 \mathrm{~Hz}$ are not significantly different; however, FTM transmissibility is significantly greater than FTA transmissibility at 40, 45 and $50 \mathrm{~Hz}$. In the current study the mean peak FTM transmissibility (1.01) occurred at $50 \mathrm{~Hz}$ and the mean peak FTA transmissibility (0.86) occurred at $30 \mathrm{~Hz}$. 
FTM transmissibility values reported in this study are in line with values reported in Harazin and Grzesik; however, reported FTA transmissibility values are lower than those reported by the same authors [25]. Harazin and Grzesik, measured floor to metatarsus transmissibility and floor to ankle transmissibility at frequencies between $4-250 \mathrm{~Hz}$ in one-third octave bands while participants adopted a standing posture with slightly bent knees. The authors reported mean floor to metatarsus transmissibility between 0.6-1.0 and mean floor to ankle transmissibility greater than one. However, it should be noted that FTA transmissibility measurements in the current study were taken at the lateral malleolus, where as Harazin and Grzesik took their measures at the medial malleolus of the ankle [25]. Differences in measurement location may account for the lower FTA transmissibility values reported in the current study. The medial malleolus is the medial head of the tibia, and the lateral malleolus is the lateral head of the fibula, and both articulate with the talus. The tibia is the second largest bone in the body and it bears a significantly larger percentage of the body's weight when standing than the fibula [33]. Therefore, it is possible that FTA transmissibility was higher when measured at the medial malleolus given the increased weight transmitted through the tibia (medial malleolus) than the fibula (lateral malleolus). Furthermore, the heel fat pad is typically thicker posterior-laterally than posterior-medially [34], which could account for increased attenuation laterally and thus a decrease in FTA when measured at the lateral malleolus.

Morioka and Griffin (2005) [26] examined differences in absolute thresholds for the perception of vibration at the fingertip with thresholds for the whole hand over the frequency range 8-500 Hz. Over the three conditions (palm, grip and fingertip), there were significant differences in absolute threshold at all frequencies (Friedman, $p<0.005$ ), except at $31.5 \mathrm{~Hz}$ (Friedman, $p=0.21$ ). It is interesting to note in the current study that the mean FTA and FTM transmissibility are almost the same at $31.5 \mathrm{~Hz}$ (Fig. 3). As the FTV exposure frequency increases beyond this point the difference in transmissibility measured at the metatarsal continues to increase and transmissibility measured at the ankle decreases.

The transmissibility results are not strictly limited to the interaction between frequency and location. The greatest mean FTM and FTA transmissibility occurred at $50 \mathrm{~Hz}$ and $30 \mathrm{~Hz}$ respectfully (Fig. 3), suggesting the formation of a local resonance at each location. Theses findings are in line with Harazin and Grzesik [26] who reported 1/3 octave band resonance frequency between 31.5-125 Hz for the metatarsal and between 25-63 Hz for the ankle. Similarly, Singh [35] reported greater transmissibility between the floor and ankle at lower FTV exposure frequencies $(3.15-10 \mathrm{~Hz})$ than higher FTV exposure frequencies $(40 \mathrm{~Hz})$. At the low frequency $(3.15-10 \mathrm{~Hz})$, FTA transmissibility averaged 1.06 with a standard deviation of \pm 0.09 .

The secondary objective of this study was to determine whether AI or mass influence vibration transmissibility through the foot. Results from two separate ANCOVAs indicate neither AI nor mass had a significant effect $(p<0.05)$ on vibration transmissibility through the foot. A recent study by Singh [35] examined FTA transmissibility to determine whether gender, arch type or mass played a role in transmissibility at both low and high frequency FTV. Eight male and eight female participants with varying arch types and mass, were exposed to FTV with a dominant frequency below $10 \mathrm{~Hz}$ and a dominant frequency between $30-40 \mathrm{~Hz}$. Similarly, no differences in vibration transmissibility through the foot were found for gender or arch type [35]. Randall and colleagues [20] also examined the resonant frequencies of standing humans and found no significant relationship between the mass, height, or mass to height ratio and measured resonant frequency. Furthermore, a study by [24] found no significant difference in FTA transmissibility based on body mass.

\subsection{Limitations of the study}

There are several limitations in the study design that should be considered when interpreting the results. First, vibration exposure magnitude and exposure frequency were not controlled independently. 
Unfortunately the research team was not able to maintain the same vibration exposure magnitude for all vibration exposure frequencies. Therefore, changes in transmissibility reported in this study may not strictly be due to changes in frequency, since vibration exposure magnitude also increased when exposure frequency increased. Furthermore, several researchers have reported transmissibility increases with increasing magnitude $[9,36,37]$. Second, although participants' foot placement was controlled and all were given the same instruction with regard to how to stand, it could not be confirmed that all participants' maintained the same posture throughout the 45-second FTV exposure period. Deviations in posture can influence vibration transmissibility due to changes in the surface contact area with the vibrating surface, which can influence the position of the bony structures and the degree of tension in different muscle groups of the trunk and the extremities, in turn changing the resonant frequency of the body structure $[1,19,21,25,36,38-41]$. Thus, variations in the ankle and knee angles could have influenced the transmission of vibration from the platform through the feet and into the lower limbs. Third, there were also limitations with the AI measurement because the centre of pressure location during foot-transmitted vibration exposure could not be confirmed.

\section{Conclusions}

This study was conducted to gain a better understanding of the biodynamic response of the foot to vibration exposure by measuring transmissibility from the FTA and FTM. There were significant differences in mean FTM and FTA transmissibility at $40 \mathrm{~Hz}, 45 \mathrm{~Hz}$, and $50 \mathrm{~Hz}$. The greatest FTM and FTA transmissibility occurred at $50 \mathrm{~Hz}$ and $30 \mathrm{~Hz}$ respectively, indicating the formation of a local resonance at each location.

\section{Future research}

Future research should evaluate the transmission of vibration through the feet to the lower limbs across a broader range of exposure frequencies while controlling for FTV exposure magnitude and the standing posture of the participants. Confirming the resonant frequencies at different locations on the foot will help determine exposure frequencies that are most likely to lead to health risks [41] in workers exposed to FTV. A greater understanding of the transmissibility properties of the foot is also needed to design controls such as isolation platforms, anti-vibration drills, and personal protective equipment such as mats and insoles for workers exposed to FTV [42]. Knowing the resonant frequency of the foot is also needed to establish standards for measuring, evaluating and determining health risks for workers exposed to FTV.

\section{Acknowledgements}

The Workplace Safety and Insurance Board of Ontario and Natural Sciences and Engineering Research Council provided funding for this study. The research team would also like to thank the study participants, and Dr. Joel Jack for early assistance with data analysis calculations in MatLab. The William Shaver Masters Scholarship in Mining Health and Safety also supported the lead author. 


\section{Conflict of interest}

The authors have no conflict of interest to report.

\section{References}

[1] Eger, T., Stevenson, J., Boileau, P.-É., Salmoni, A., VibRG. Predictions of health risks associated with the operation of load-haul-dump mining vehicles: Part 2 - Evaluation of operator driving postures and associated postural loading. International Journal of Industrial Ergonomics, 2008, 38, pp. 801-815.

[2] Thompson, A., House, R., Eger, T., \& Krajnak, K. Vibration-white foot: A case report. Occupational Medicine, 2010, 60, pp. 572-574.

[3] Leduc, M., Eger, T., Godwin, A., Dickey, J.P., \& House, R. Examination of vibration characteristics, and reported musculoskeletal discomfort for workers exposed to vibration via the feet. Journal of Low Frequency Noise, Vibration and Active Control, 2011, 30(2), pp. 197-206.

[4] Dickey, J., Oliver, M., Boileau, P.-E., Eger, T., Trick, L., \& Edwards, M. Multi-axis sinusoidal whole-body vibrations: Part I - How long should the vibration and rest exposures be for reliable discomfort measures? Journal of Low Frequency Noise, Vibration and Active Control, 2006, 25(3), pp. 175-184.

[5] Laeger, U. Vibration-induced white toes. Herning Centralsygehus, arbejdsmedicinsk klinik, 1994, 156(34), pp. 4836-8.

[6] Toibana, N., Ishikawa, N., Sakakaibara, H., Yamada, S. Raynaud's phenomenon of fingers and toes among vibrationexposed patients. Nagoya Journal of Medical Science, 1994, 57, pp. 121-128.

[7] Hedlund, U. Raynaud's Phenonmenon of fingers and toes of miners exposed to local and whole-body vibration and cold. International Archives of Occupational and Environmental Health, 1989, 61, pp. 457-461.

[8] Bovenzi, M. Health effects of mechanical vibration. G Ital Med Lav Erg, 2005, 27(1), pp. 58-64.

[9] Griffin, M.J. Measurement, evaluation, and assessment of peripheral neurological disorders caused by hand-transmitted vibration. International Archives of Occupational and Environmental Health, 2008, 81, pp. 559-573.

[10] Hagberg, M., Burstrom, L., Lundstrom, R., \& Nilsson, T. Incidence of Raynaud's phenomenon in relation to hand-arm vibration exposure among male workers at an engineering plant a cohort study. Journal of Occupational Medicine and Toxicology, 2008, 3(13).

[11] Hashiguchi, T., Yanagi, H., Kinugawa, Y., Sakakibara, H., \& Yamada, S. Pathological changes of finger and toe in patients with vibration syndrome. Nagoya Journal of Medical Science, 1994, 57, pp. 129-136.

[12] Sakakibara, H., Akamatsu, Y., Miyao, M., Kondo, T., Furuta, M., Yamada, S., et al. Correlation between vibrationinduced white finger and symptoms of upper and lower extremities in vibration syndrome. International Archives of Occupational and Environmental Health, 1998, 60, pp. 285-289.

[13] Sakakibara, H., Hashiguchi, T., Furuta, M., Kondo, T., Miyao, M., \& Yamada, S. Circulatory disturbances of the foot in vibration syndrome. International Archives of Occupational and Environmental Health, 1991, 63, pp. 145-148.

[14] Dong, R.G., Schopper, A.W., McDowell, T.W., Welcome, D.E., Wu, J.Z., Smutz, W.P., Warren, C., Rakheja, S. Vibration energy absorption (VEA) in human fingers-hand-arm system. Medical Engineering \& Physics, 2004, 26(6), pp. 483-492.

[15] Bovenzi, M. A prospective cohort study of exposure-response relationship for vibration-induced white finger. Occup Environ Med, 2010, 67(1), pp. 38-46.

[16] International Organization for Standardization. ISO 2631: Mechanical vibration and shock - Evaluation of human exposure to whole-body vibration - whole-body vibration - Part 1: General Requirements. Geneva, 1997.

[17] International Organization for Standardization. ISO 5349-1: Mechanical vibration - Guidelines for the measurement and the assessment of human exposure to hand-transmitted vibration. Geneva, 2004.

[18] Bovenzi, M. Exposure-response relationship in the hand-arm vibration syndrome: An overview of current epidemiology research. International Archives of Occupational and Environmental Health, 1998, 71, pp. 509-519.

[19] Griffin, M.J. Handbook of Human Vibration. Academic Press, London, 1990.

[20] Randall, J.M., Matthews, R.T., \& Stiles, M.A. Resonant frequencies of standing humans. Ergonomics, 1997, 40(9), pp. 879-886.

[21] Paddan, G.S., \& Griffin, M.J. A review of the transmission of translational seat vibration to the head. Journal of Sound and Vibration, 1998, 215(4), pp. 863-882.

[22] Mansfield, N.J. Human response to vibration. CRC, Press, New York, 2005.

[23] Forta, N.G., Griffin, M.J., \& Morioka, M. Difference thresholds for vibration of the foot: Dependence on frequency and magnitude of vibration. Journal of Sound and Vibration, 2011, 330, pp. 805-815.

[24] Singh, P. Evaluation of foot-transmitted vibration and transmissibility characteristics of mining boots and insoles. Unpublished Masters Thesis, Laurentian University, Sudbury, Ontario, Canada, 2013. 
[25] Harazin, B., \& Grzesik, J. The transmission of vertical whole-body vibration to the body segments of standing subjects. Journal of Sound and Vibration, 1998, 215(4), pp. 775-787.

[26] Morioka, M., \& Griffin, M.J. Frequency weightings for fore-and-aft vibration at the back: Effect of contact location, contact area, and body posture. Industrial Health, 2005, 48, pp. 538-549.

[27] Cavanagh, P.R., \& Rogers, M.M. The arch index: A useful measure from footprints. J Biomech, 1987, 20(5), pp. 541-551.

[28] Jack, R.J., Oliver, M., Dony, R., Dickey, J.P. The use of multiple resolution cross-correlations to align simultaneously collected whole-body vibration data. Journal of Low Frequency Noise, Vibration and Active Control, 2008, 27(2), pp. 121-133.

[29] Smith, S.W. The scientist and engineer's guide to digital signal processing, 2nd edition. California Technical Publishing. San Diego, California, 1999.

[30] Mansfield, N.J. Impedance methods (apparent mass, driving point mechanical impedance and absorbed power) for assessment of the biomechanical response of the seated person to whole-body vibration. Industrial Health, 2005, 43, pp. 378-389.

[31] Tabachnick, B.G., \& Fidell, L.S. Using multivariate statistics (5th ed.). Boston: Allyn and Bacon, 2007.

[32] Howell, D.C. Statistical methods for psychology (6th ed.). Thomson Wadsworth, 2007.

[33] Wang, Q., Whittle, M., Cunningham, J., \& Kenwright, J. Fibula and its ligaments in load transmission and ankle joint stability. Clinical Orthopaedics and Related Research, 1996, Sept(330), pp. 261-270.

[34] Sopher, R., Nixon, J., McGinnis, E., \& Gefen, A. The influence of foot posture, support stiffness, heel pad loading and tissue mechanical properties on biomechanical factors associated with a risk of heel ulceration. Journal of the Mechanical Behavior of Biomedical Materials, 2011, 4, pp. 572-582.

[35] Singh, P., Eger, T., Dickey, J., House, R., \& Oliver, M. Evaluation of gender differences in foot-transmitted vibration. Canadian Acoustics, 2011, 39(2), pp. 62-63.

[36] Mansfield, N.J., Holmlund, P., Lundstrom, R., Lenzuni, P., Nataletti, P. Effect of vibration magnitude, vibration spectrm and muscle tension on apparent mass and cross axis transfer functions during whole-body vibration exposure. Journal of Biomechanics, 2006, 39, pp. 3062-3070.

[37] Dong, R.G., Welcome, D.E., Xu, X.S., Warren, C., McDowell, T.W., Wu, J.Z. 3-D mechanical impredances distributed at the fingers and palm of the hand. Proceedings for the Canadian Acoustics: 12th International Conference on Hand-Arm Vibration. Ottawa, Canada. 2011, 39(2), pp. 46-47.

[38] Zimmerman, C.L., Cook, T.M. Effects of vibration frequency and postural changes on human responses to seated whole body vibration exposure. Int Arch occup Environ Health, 1997, 9, pp. 165-179.

[39] Adewusi, S., Rakheja, S., Marcotte, P. Analyses of distributed absorbed power responses of the human hand-arm system in the bent- and extended-arm postures. Proceedings for the Canadian Acoustics: 12th International Conference on Hand-Arm Vibration. Ottawa, Canada. 2011, 39(2), pp. 50-51.

[40] Kitazaki, S., \& Griffin, M.J. A modal analysis of whole-body vertical vibration, using a finite element model of the human body. Journal of Sound and Vibration, 1997, 200(1), pp. 83-103.

[41] Furuta, M., Sakakibara, H., Miyao, M., Kondo, T., Yamada, S. Effects of vibration frequency on finger blood flow. Int Arch Occup Environ Health, 1991, 63, pp. 221-224.

[42] Leduc, M., Eger, T., Godwin, A., Dickey, J.P., \& Oliver, M. Evaluation of properties of anti-fatigue mats used by workers exposed to foot-transmitted vibration. Proceedings from Canadian Acoustics, 2011, 39(2), pp. 88-89. 